\title{
Spatio-temporal mapping of salinity in the heterogeneous coastal aquifer
}

\author{
Ali Ranjbar ${ }^{1} \cdot$ Majid Ehteshami $^{2}$
}

Received: 26 May 2018 / Accepted: 11 February 2019 / Published online: 25 February 2019

(c) The Author(s) 2019

\begin{abstract}
The interface between freshwater and saltwater in the coastal aquifer is a main factor that is affected by environmental threat and excessive pumping. In this study, a density-dependent numerical model was utilized to simulate the salt distribution of a coastal aquifer in the Talar region near the Caspian Sea, Mazandaran, Iran. To simulate the aquifer salinity and head contour over 2-year stress period, SEAWAT model in groundwater modeling system (GMS) package was used. Moreover, different variogram models based on 21 observation points were tested to find a best fit between observed and simulated total dissolved solids (TDS). A genetic algorithm was coupled with GMS model to identify the optimal sill ratio, range, and nugget value of each variogram. The interface between saltwater and freshwater estimated by the optimal variogram model and compared with the result of sharp interface and variable density flow assumption. The result indicates that the optimal Gaussian variogram as best estimation of spatial TDS can be used for estimation of temporal salinity with a coefficient determination about 0.91 . Also, an integration of spherical and exponential variogram shows the high performance for mapping spatial TDS and neutralizes the underestimation behavior of single variogram. A comparison between variogram model and analytical solution indicates that the interface length in the eastern part of aquifer for Gaussian model is relatively small than sharp interface relation. The maximum saltwater penetration based on sharp interface and SEAWAT results is about $1600 \mathrm{~m}$ and $1750 \mathrm{~m}$, respectively. Additionally, maximum saltwater intrusion is observed in the western part of aquifer which has a large number of active wells.
\end{abstract}

Keywords Saltwater intrusion $\cdot$ Spatio-temporal estimation $\cdot$ Optimal variogram $\cdot$ Density-dependent flow $\cdot$ Sharp interface assumption

\section{Introduction}

Seawater intrusion (SWI) into the aquifer in many coastal areas is a global issue. Several studies have been carried out to study the mechanism of seawater encroachment in different coastal regions of the world (Huang et al. 2013). An thin transition zone with variable salt concentration exists between freshwater and saltwater that its location is mostly influenced by excessive pumping and environmental

Ali Ranjbar

aranjbar@mail.kntu.ac.ir

Majid Ehteshami

ehteshami@kntu.ac.ir

1 Water Resources Department, Civil Engineering Faculty, K. N. Toosi University of Technology, Tehran, Iran

2 Environment Department, Civil Engineering Faculty, K. N. Toosi University of Technology, Tehran, Iran threats such as sea level rise and tidal fluctuations (Langevin and Zygnerski 2013; Roy and Datta 2017). Several mathematical tools have been developed to study the location of freshwater-saltwater interface over the time under different patterns of pumping and recharge (Lu et al. 2013). These tools include some analytical solutions and numerical models based on the sharp interface assumption and variables density flow, respectively (Dokou and Karatzas 2012; Werner et al. 2013). Numerical models have been carried out to simulate the temporal variation of saltwater interface in the real aquifers under different patterns of pumping and recharge, whereas analytical approaches were used to study the location of saltwater wedge in the hypothetical aquifer such as Henry and Elder problems (Lu et al. 2013).

There are many applications of SEAWAT (Langevin et al. 2008), SUTRA (Voss 1984), FEFLOW (Diersch 2005), and FEMWATER (Lin et al. 1997) with optimization models to find the optimum location and recharge rates of pumping 
wells. There are the combination of optimization algorithms with those of FEFLOW (Nocchi and Salleolini 2013), SEAWAT (Kourakos and Mantoglou 2009), and FEMWATER (Dhar and Datta 2009). Abd-Elhamid and Javadi (2011) attempted to assess the effect of abstraction, desalination, and recharge (ADR) technique for the maximization of pumping rate in the hypothetical aquifer using the combination of SUTRA model with genetic algorithm.

Many studies evaluated the impact of sea level rise and tidal effect on SWI using these numerical models. The capability of FEMWATER model to simulate the salinity level under 1-m sea level rise in the Mediterranean coast of Morocco was reported by Carneiro et al. (2010). Colombani et al. (2016) utilized SEAWAT to assess the impact of sea level rise on quantity of SWI by 2050 in the unconfined coastal aquifer of Po Delta, Italy. They showed that overextraction from western part of aquifer has a more significant influence on SWI than the sea level rise. Abd-Elhamid et al. (2016) used SEAWAT model to investigate seawater intrusion in the Nile Delta aquifer under different combinations of scenarios such as excessive pumping and sea level rise. Pool et al. (2014) investigated the effect of tidal mixing number on shape and location of transition zone in the hypothetical aquifer using SUTRA code. Moreover, many works implemented SEAWAT model to investigate the impact of long-term sea level rise on SWI in the coastal regions of many parts of the world such as Nagapattinam aquifer of Tamil Nadu, India (Gopinath et al. 2016), Weifang city of Shandong province, China (Zeng et al. 2016).

A large number of recent studies derived analytical solutions to investigate saltwater toe movement in response to variation of sea level. Mazi et al. (2013) developed an analytical model to assess the responses of saltwater wedge to sea level rise in the aquifer with different bed slopes. $\mathrm{Lu}$ et al. (2015) presented analytical approach to measure the effect of $1-\mathrm{m}$ sea level rise on saltwater toe location in the unconfined and confined aquifer considering a general head boundary for inland side.

This review of literature indicates that all studies evaluated the response of aquifer salinity due to environmental threats such as sea level rise and over-pumping. Despite progress in saltwater intrusion studies, there are gaps in many key parameters such as shoreline geomorphology and variable density flow assumptions (Werner et al. 2013).

To overcome these problems, several approaches have been extended in the literature for estimating the spatiotemporal variation of different groundwater indicators such as total dissolved solids (TDS) and chloride concentration using geostatistical tools (Gneiting et al. 2006; Fuentes et al. 2008). These geostatistical models were developed to interpolate the salinity distribution in the temporal and spatial condition using existence observation data without considering the effect of environmental treats (Agoubi et al. 2013).
Dhar and Patil (2011) developed a fuzzy kriging system to estimate the spatial variation of salinity using the small number of monitoring networks, in which fuzzy spatial interpolation was integrated with groundwater flow and salinity equations. Khattak et al. (2014) demonstrated that spatial statistical tools such as kriging approaches were better than the traditional interpolation techniques for hydrological predictions. Venkatramanan et al. (2016) characterized the main factors that influence the groundwater pollution using multivariate statistical analyses and variogram technique. They used kriging and interpolation approaches to assess the spatial correlation of different saline ion in Miryang city. Efforts to measure the saltwater intrusion spatially need the geophysical and experimental data that integrated with geostatistical approaches (Kumar et al. 2015). For this purpose, geostatistical approaches such as kriging interpolation was coupled with geochemical models (Tomaszkiewicz et al. 2014). The application of kriging approach with different variogram and sensitive parameters for transient salinity estimation was reported by Triki et al. (2014). However, an accurate prediction of groundwater quality parameters is dependent on selecting appropriate variogram that is consistent with nature of geostatistical features (Akbarzadeh and Ghahraman 2013).

The aim of this study is to identify the efficient variogram model that highly correlated with observation TDS data in three dimensions. For this purpose, different variogram models including Gaussian, spherical power, and exponential were developed to map TDS distribution in vertical and horizontal directions. The result of optimal variogram was compared with the sharp interface and density-dependent flow assumption in term of the statistical index.

\section{Methodology and methods}

\section{Methodology}

This study develops an efficient geostatistical model to project the spatial and temporal distribution of TDS in coastal aquifer of Talar. Then, the result of variogram models was compared with sharp interface and variable density flow assumption. For this purpose, GMS model is considered to generate different variograms with their calibrated parameters using geophysics data. Geostatistical tools were implemented to assess the spatial and temporal correlation of geophysics data in the Talar aquifer. GA algorithm is linked with GMS software to identify the optimal structure of variogram models with the goal of increasing spatial correlation between estimated and observed TDS. The GMS-GA model was executed recursively to converge the optimal solution of decision variables that reduce the variogram estimation error. Finally, saltwater interface was measured using finite 
difference SEAWAT model and sharp interface approach. The location of interface by three models that were investigated and the area with risk of saltwater intrusion were determined.

\section{Study area}

Talar aquifer with $890 \mathrm{~km}^{2}$ area is located at the southern part of Caspian sea, vicinity of Mazandaran province, Iran, between $52^{\circ} 22^{\prime} \mathrm{E}$ to $53^{\circ} 42^{\prime} \mathrm{E}$ longitude and $36^{\circ} 43^{\prime} \mathrm{N}$ to $37^{\circ} 30^{\prime} \mathrm{N}$ latitude (Fig. 1). The slope of the main basin in $\mathrm{N}-\mathrm{W}$ and $\mathrm{N}-\mathrm{E}$ direction is increased from $1204 \mathrm{~m}$ to $3760 \mathrm{~m}$ and $3307 \mathrm{~m}$, respectively. The boundary conditions of the aquifer are a constant head in the southern part with TDS about $12.6 \mathrm{~g} \mathrm{~L}^{-1}$ and two rivers including Siahrood and Babolrood river in west and east of aquifer (see Fig. 1).

Average yearly precipitation through the study area varies from 635 to $840 \mathrm{~mm} \mathrm{year}^{-1}$. The mean annual evaporation is $133 \mathrm{~mm}_{\text {year }}^{-1}$ and $206 \mathrm{~mm}_{\text {year }}{ }^{-1}$ for July and August, respectively.
The geo-electric study of Talar area illustrates that aquifer layer usually is composed of bedrock and quaternary deposits such as alluvial sands, clay, and gravel. The major part of aquifer bedrock includes sand and fine-grained deposit, in which the elevation is increased from 15 to $165 \mathrm{~m}$ above average sea level. The permeability information comes from 21 borehole data and geophysical records at different depth of aquifer. The geological part of aquifer categorized many Quaternary units in which the hydraulic conductivity varied between 0.14 and $0.2 \mathrm{~m}$ day $^{-1}$.

The maximum annual drawdown in observation wells for different needs is fluctuated between $-0.1 \mathrm{~m}$ at southern part and $-1.2 \mathrm{~m}$ in center of aquifer, respectively. The total pumping rate from 629 shallow wells is $195 \mathrm{Mm}^{3} /$ year, where $91 \%$ of extracted water is used for irrigation. However, $82 \%$ of deep wells are located in agricultural lands and include the vast part of total discharge.

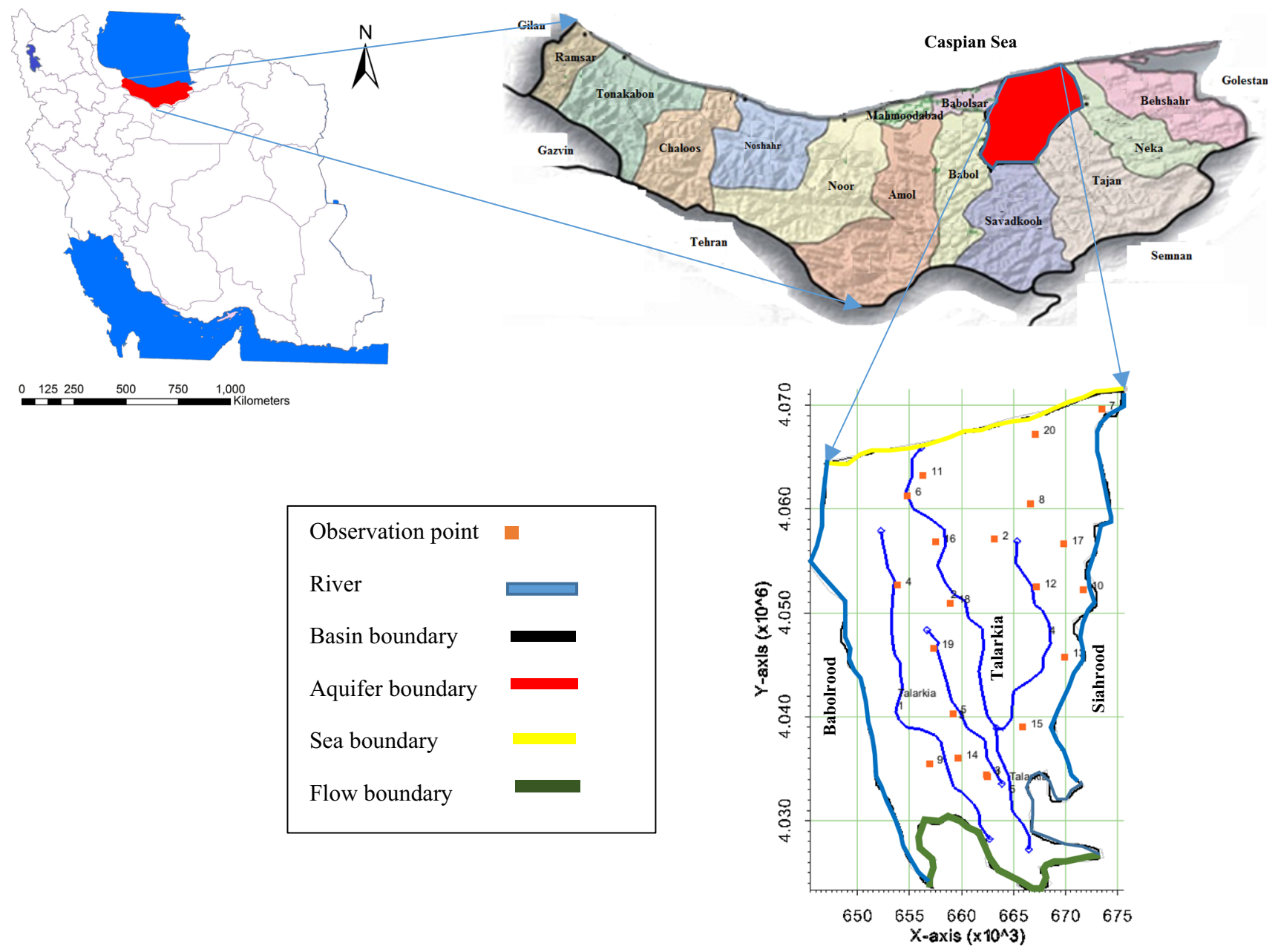

Fig. 1 Boundary conditions and monitoring points of Talar aquifer 


\section{Numerical and analytical model}

In this study, a finite difference SEAWAT model was used to investigate the salinization process in the variable density flow. Moreover, the sharp interface assumption presented by Ghyben-Herzberg is utilized for measurement of saltwater wedge (Strack 1976).

SEAWAT solves the contaminant transport and groundwater equation simultaneously using the combination of MODFLOW and MT3DMS. In this study, SEAWAT in the framework of GMS 10 is used for the simulation of TDS in the Talar aquifer.

The mathematical relationship which shows the head distribution in homogenous coastal aquifer can be written as below (Ranjbar and Mahjouri 2018):

$\nabla\left(K(\nabla h+\eta C \nabla z)=S_{s} \frac{\partial h}{\partial t}+n \eta \frac{\rho}{\rho_{0}} q\right.$

where $K$ is the hydraulic conductivity vector $\left(L T^{-1}\right), h$ is freshwater head $(L), \eta$ is density coupling coefficient, $C$ is salt concentration $\left(M L^{-3}\right), Z$ is reference head station $S_{\mathrm{s}}$ is specific storage $\left(L^{-1}\right), t$ is time $(T), n$ is porosity, $q$ is inflow rate, $\rho$ is density of fluid in transition zone $\left(M L^{-3}\right), \rho_{0}$ is density of freshwater $\left(M L^{-3}\right)$. $h$ represents freshwater head and is expressed as below:

$h=\frac{p}{\rho_{0}}+Z$

where $P$ is saltwater pressure. Density coupling coefficient is written as below:

$\eta=\frac{\varepsilon}{c_{\max }}$

$\varepsilon=\frac{\rho_{\max }}{\rho_{0}}-1$

Here, $c_{\max }$ is concentration corresponding to maximum density $\left(\rho_{\max }\right)$ and the relation between $\rho$ and $\rho_{0}$ can be expressed as below:

$\rho=\rho_{0}(1+\eta c)=\rho_{0}\left(1+\rho_{\mathrm{r}}\right)$

Here, $\rho_{\mathrm{r}}$ represents relative density.

The general form of differential governing equation for plume transport in aquifers without sorption and decay is expressed as below (Zheng and Wang 1999):

$\nabla(D \nabla C)-\nabla\left(V_{a} C\right)+m-\frac{\rho^{*}}{\rho} q c=\frac{\partial c}{\partial t}$

where $D=$ dispersion tensor $\left(L^{2} T^{-1}\right), V_{a}=$ leakage velocity $\left(L T^{-1}\right), q$ is the source rate of groundwater $\left(L^{3} T^{-1}\right), m=q C_{\mathrm{m}}$ denotes the artificial mass rate $\left(M L^{3} T^{-1}\right)$.
In the sharp and diffusive interface methods, a sharp and diffusive zone exists between freshwater and saltwater, where the concentration of saltwater in the diffusive zone increase from 0 to seawater concentration $(12.6 \mathrm{~g} / \mathrm{L})$. The sharp interface relationship in the steady state can be written as below (Strack 1976):

$h_{\mathrm{s}}=\frac{\rho_{\mathrm{f}}}{\rho_{\mathrm{s}}-\rho_{\mathrm{f}}} h_{\mathrm{f}}$

where $h_{\mathrm{s}}$ is the difference between sea level and interface height, $h_{\mathrm{f}}$ is the height of freshwater from sea level. $\rho_{\mathrm{s}}$ and $\rho_{\mathrm{f}}$ are the density of saltwater and freshwater, respectively.

\section{Geostatistical modeling}

Geostatistical approaches are mathematical equations that focus on the estimation of unmeasured spatial data using monitoring scatter points (Liebhold et al. 1993). In this methodology, the points that are close together assign the high value than points that are separated.

In the kriging technique, the points near each other include the equal value of spatial correlation. If the points are extensively disjointed each other, the correlation is considered zero. Thus, the correlation between points is measured based on a degree of the spatial factor. This feature allows geostatistical model utilized from various data point to reduce the uncertainty originated from the spatial parameter of the aquifer (Yoo et al. 2018). Kriging uses many regression equations to minimize variance of point value using a covariance model as expressed below (Kitanidis 1997):

$\hat{Z}\left(s_{0}\right)=\sum_{i=1}^{n} \lambda_{i} Z\left(s_{i}\right)+k$

where $\hat{Z}\left(s_{0}\right)$ is the estimated value of location $s_{0}$ based on observation points $Z\left(s_{\mathrm{n}}\right), \ldots, Z\left(s_{1}\right)$ for locations $s_{\mathrm{n}}, \ldots, s_{1}$, respectively, $k$ and $\lambda_{\mathrm{i}}$ are weights which minimize the variance of error $\left(\sigma^{2}\right)$ between estimated and observed value for point $s_{0}$ as expressed below:

$\sigma^{2}=E\left[Z\left(s_{0}\right)-\hat{Z}\left(s_{0}\right)\right]^{2}$

Additionally, the average value of points is independent from spatial variations of points. Based on the stationary assumption, the average value of existence points is constant and a variogram $\gamma$ can be fitted between all points. The covariogram is a traditional method to identify the spatial dependencies. However, the inability of covariogram in the estimation of points value cause to develop the nearly related equation known semivariogram $\gamma$ as defined below:

$\gamma(h)=\frac{1}{2} E\left[Z\left(s_{0}\right)-\hat{Z}\left(s_{0}\right)\right]^{2}, \quad\left\|s_{\mathrm{i}}-s_{\mathrm{j}}\right\|=h$ 
While the analytical semivariogram provides a valuable conceptual framework for estimation of statistical data, however, many mathematical models with effective parameters are used to predict geostatistical data. The simplest and popular semivariogram used in groundwater modeling is spherical variogram as defined below (Sadeghiyan et al. 2013):

$\gamma(h)=\left\{\begin{array}{ll}c_{0}+c\left(\frac{3}{2} \frac{\|h\|}{a}-\frac{1}{2} \frac{\|h\|^{3}}{a^{3}}\right) & 0<\|h\| \leq a, h \in R^{d}, d=1,2,3 \\ c_{0}+c & \|h\| \geq a\end{array}\right\}$

Here, $r$ indicates the maximum bound of positive spatial dependencies, $c=\sigma^{2}$ and $c_{0}$ are called sill of semivariogram and nugget effect, respectively. The nugget index indicates the discontinuity at the beginning of semivariogram and is representative for a pure spatial correlation. Also, the sill index represents the point in which the semivariogram levels off. Regarding the smoothness of spherical semivariogram in case of differentiability, it is appropriate for the geostatistical data, in which the correlation of point in the large distance is close to zero. The exponential semivariogram is the suitable model for geostatistical data because correlation between value of point is a nonzero value. This variogram can be defined as below (Mahdianfard and Mohammadzadeh 2015):

$\gamma(h)=c_{0}+c\left(1-e \frac{-\|h\|}{a}\right), \quad h \in R^{d}, \quad d \geq 1$.

Also, the Gaussian semivariogram has the parabolic behavior, and it is appropriate for smoothly varying geostatistical data. The power semivariogram has not the covariance function, and sill value therefore, and it is compatible with geostatistical data that are showing fractal behavior. The Gaussian and power model can be written as follows (Mahdianfard and Mohammadzadeh 2015):

$\gamma(h)=c_{0}+c\left(1-e \frac{-\|h\|^{2}}{a^{2}}\right), \quad h \in R^{d}, \quad d \geq 1$

$\gamma(h)=c_{0}+\alpha\|h\|^{\lambda} \quad 0<\lambda<2, \quad h \in R^{d}, \quad d \geq 1$

There are many different techniques to fit possible semivariogram surface to geostatistical data (Schabenberger and Gotway 2017). The main object is to construct an estimation of the semivariogram based on existing data. This experimental semivariogram is then utilized to estimate the value of unseen data point. The simple way to construct experimental semivariogram is dividing the range of $h$ into many lags $h_{\mathrm{i}}$ as indicated in Fig. 2.

The semivariogram will be constructed to fit the observation points in different lags using mathematical function which should be implemented to forecast values at unmeasured locations (Deutsch and Tran 2002). Kriging is an optimal method for prediction of geographical space with low uncertainty in spatial parameters (Oliver 2010). The variogram curve is increment function that has the small value for low values of $h$, and with increasing of $h$, this curve converged to a constant value as illustrated in Fig. 3.

In this research, the spatial variation of the TDS concentration was mapped by different variograms and interpolation model around the monitoring points, and then, the area threatened by saltwater intrusion under pumping activity was determined. To find the optimal value of variogram parameters to achieve the best performance between observed and estimated TDS, the genetic algorithm was developed.

\section{Genetic algorithm (GA)}

GA algorithm is in the category of evolutionary algorithms, and it is implemented to find the global solution in a problem

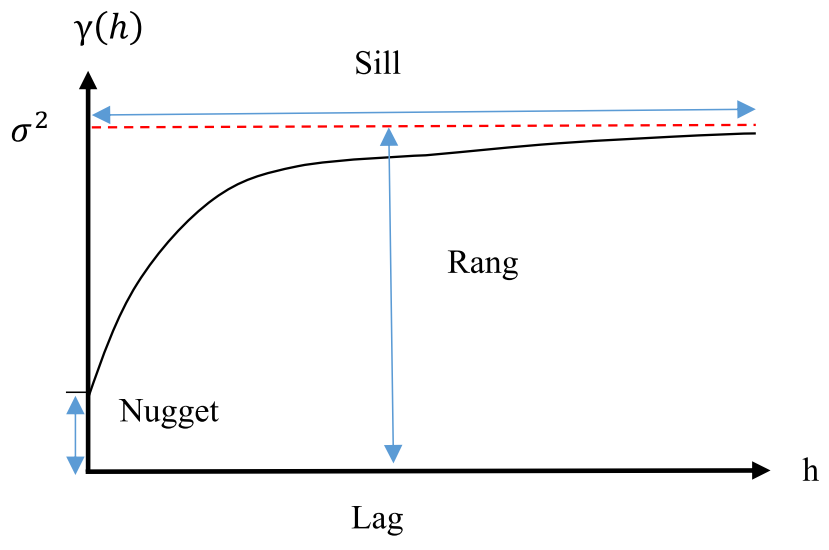

Fig. 3 Key parameters of variogram

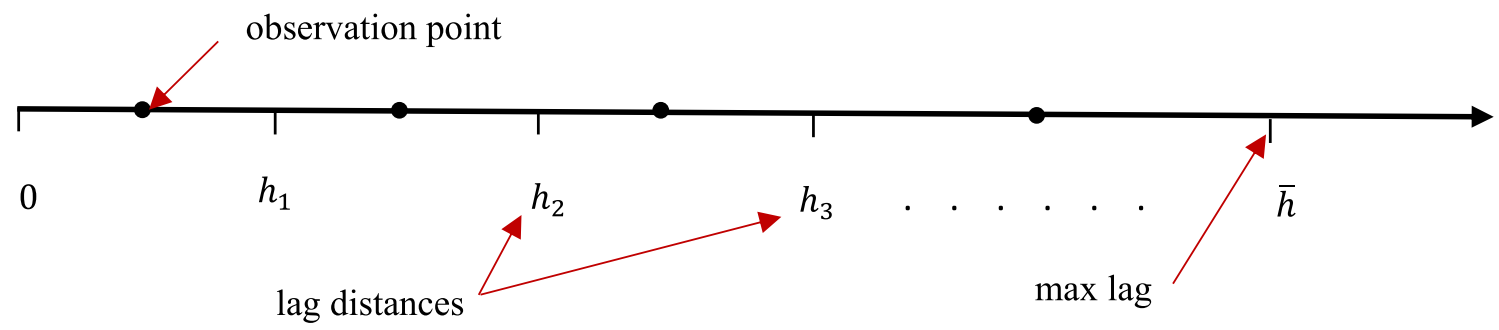

Fig. 2 Component of an experimental semivariogram based on observation data 
with the local optimum point. Optimization models based on searching space were divided in gradient-based and global techniques. In the gradient method, the optimal solution is identified using descent direction of the objective function, while in the global method, decision variables are scored based on its fitness. Unlike the gradient method, the search space area is evaluated in this algorithm that results in finding a global optimum. Therefore, the optimal answers generated by global approach have the most robustness with low uncertainty. GA uses the crossover, selection, and mutation factors to identify the solution with the best fitness. The aim of crossover process is to enhance the features (children) of GA from the prior generation. Mutation is the process of generating best individuals from existence population using a comparison between several genes. The mutation rate and crossover fraction regulate individuals numbers which are created by mutation and crossover steps, respectively (Maschio et al. 2008). Regarding the independency between individuals, it causes decrease in time of objective function evaluation, especially when the GA was linked to the simulation model.

In this research, GMS model was integrated with GA algorithm to find the optimal value of nugget effect, contribution, range, and azimuth angle of each variogram. The variation of each decision variables was considered continues around the calibrated value of parameters. The objective function of optimization model was defined the root-meansquare error between observed and estimated TDS in 21 monitoring locations.

\section{Performance evaluation}

To determine the accuracy of optimum variograms model, the TDS value measured in 21 monitoring point and used as judgment for performance of each variogram. The statistical index was used to measure the performance of each variogram approach as presented below:

$$
\begin{aligned}
& \mathrm{CD}=1-\frac{\sum_{i=1}^{n}\left(T D S_{\mathrm{s}}-T D S_{\mathrm{o}}\right)^{2}}{\sum_{i=1}^{n}\left(T D S_{\mathrm{o}}-\frac{1}{N} \sum_{i=1}^{n} T D S_{\mathrm{o}}\right)^{2}}, \\
& \mathrm{MSE}=\frac{1}{n} \sum_{i=1}^{n}\left(T D S_{\mathrm{s}}-T D S_{\mathrm{o}}\right), \\
& \mathrm{RMSE}=\sqrt{\frac{\sum_{i=1}^{n}\left(T D S_{\mathrm{s}}-T D S_{\mathrm{o}}\right)^{2}}{n}} \\
& D R_{\max }=\log \left(\frac{T D S_{\mathrm{s}}}{T D S_{\mathrm{o}}}\right)
\end{aligned}
$$

where $\mathrm{CD}$ is coefficient of determination between observed concentration $\left(T D S_{\mathrm{o}}\right)$ and estimated concentration $\left(T D S_{\mathrm{s}}\right)$, RMSE and MSE are the root-mean-square error and mean standardized error between observed and estimated concentration, respectively, and $D R_{\max }$ represents discrepancy ratio where the value of zero shows the best fit between observed and estimated concentration.

\section{Results and discussion}

\section{Numerical simulation}

The numerical simulation of seawater intrusion is generated using SEAWAT model. The Talar domain in plan is divided into $250 \mathrm{~m} \times 250 \mathrm{~m}$ cells and vertically divided into three layers. The simulation period was considered 2 years and discretized into monthly stress periods. Table 1 shows the range of parameters used for the spatial and temporal simulation of the aquifer (Fatemi and Ataie-Ashtiani 2008). The initial TDS for northern (Caspian sea) and southern part (Inland boundary) of aquifer was set $12.6 \mathrm{~g} \mathrm{~L}^{-1}$ and $0 \mathrm{~g} \mathrm{~L}^{-1}$, respectively. The Caspian sea boundary was considered as constant head with a head of $11 \mathrm{~m}$. A general head boundary (GHB) was set for southern part in which flow entered the domain. To simulate the Talarkia, Siahrood and Babolrood river, the River package implemented with the average stage of $38 \mathrm{~m}$ and the conductance of $4500 \mathrm{~m}^{2} \mathrm{day}^{-1}$.

To utilize the model parameters for a stochastic and parameter estimation run, the groundwater flow equations solved using MODFLOW-2000 with forward run. The model was calibrated using PEST 13.0 interface across one observation well located near the shoreline (see Fig. 3). The observation between 2011 and 2013 was implemented for calibration and validation of groundwater head and TDS

Table 1 Used parameters for quantity and quality simulation of aquifer

\begin{tabular}{llll}
\hline Parameter & Symbol & Value & Unit \\
\hline Longitudinal hydraulic conductivities & $K_{\mathrm{xx}}$ & $15-25$ & $\mathrm{~m} \mathrm{day}^{-1}$ \\
Transverse hydraulic conductivities & $K_{\mathrm{yy}}$ & $0.14-0.2$ & $\mathrm{~m} \mathrm{day}^{-1}$ \\
Vertical hydraulic conductivities & $K_{\mathrm{zz}}$ & 0.32 & $\mathrm{~m} \mathrm{day}^{-1}$ \\
Specific yield & $S_{\mathrm{y}}$ & $0.24-0.1$ & - \\
Porosity & $\varphi$ & 0.24 & - \\
Longitudinal dispersivity & $\alpha_{\mathrm{L}}$ & 77.05 & $\mathrm{~m}$ \\
Transverse dispersivity & $\alpha_{\mathrm{T}}$ & 14.10 & $\mathrm{~m}$ \\
Density difference ratio & $\varepsilon$ & 0.025 & - \\
Vertical recharge rate & $V_{\mathrm{r}}$ & 0.024 & $\mathrm{~m} \mathrm{day}$ \\
Reference hydraulic head & $h_{\mathrm{f}}$ & 1.65 & $\mathrm{~m}$ \\
Molecular diffusion & $d_{0}$ & $7.7 \times 10^{-6}$ & $\mathrm{~m}^{2} \mathrm{~s}^{-1}$ \\
Anisotropy rate & $\lambda$ & $5-100$ & - \\
\hline
\end{tabular}


concentration. Four model parameters for calibration of groundwater heads were including three hydraulic conductivities and inflow from inland side $(Q)$.

Figure 4 shows the TDS distribution using SEAWAT model in the steady state for calibrated value of permeability based on 21 observation wells between 2011 and 2013.

\section{Variogram model}

Different interpolation and variogram models were implemented to forecast the spatial distribution of TDS concentration in two time steps. For interpolating of TDS, two popular technique including inverse distance and the natural neighbor was developed and its performance compared with variogram models (spherical, exponential, Gaussian and power model). As illustrated in Fig. 2, the aquifer has $25 \mathrm{~km} \times 31 \mathrm{~km}$ dimensions that divided into $250 \mathrm{~m} \times 250 \mathrm{~m}$ mesh area, and therefore, variograms can be assigned the range value between 0 and $40 \mathrm{~km}$ in $x$-direction and 0 to $25 \mathrm{~km}$ in $y$-direction. The optimal value of the variogram parameters was calculated by GA algorithm and is presented in Table 2. As seen, the nugget value for the spherical and exponential model is near the zero, and it is smaller than power model (159106). Regarding the low value of sill factor for power model, it has smooth surface. Additionally, only the spherical model between all variograms has a sill value $(70,749)$ more than nugget effect $(17,713)$. However, the summation of nugget effect and ratio of it to sill value is low than 0.5 , and thus, the spatial prediction is acceptable.
Table 2 Optimal value of parameters for different variogram models

\begin{tabular}{llllll}
\hline Model & Nugget & Sill & Range & Azimuth angle & Anisotropy \\
\hline Spherical & 17,713 & 70,749 & 1625 & 20 & 1 \\
Exponential & 15,713 & 11,651 & 11,920 & 20 & 1 \\
Gaussian & 35,321 & 5231 & 14,085 & 20 & 1 \\
Power & 159,106 & 1771 & 0.63 & 20 & 1 \\
\hline
\end{tabular}

The small value of range index for all variogram indicates that points located in the distance have the low effect on variogram curve.

The predicted and experimental variograms for different algorithms are shown in Fig. 5. The red curve corresponding to the optimal variogram that is fitted to experimental variogram (dotted line). As shown in Fig. 5, the spatial Gaussian and spherical model with the optimal parameters shows the equal value for long distance $(\geq 12,000 \mathrm{~m})$. Among four variograms, the power model shows the low fit to the experimental case, while the goodness of fit is observed for exponential variogram in the small distance $(\leq 1000)$. In addition, the exponential model was more sensitive to the variation of lag distance than another variogram.

To judge the accuracy of the spatial variogram model, the estimated TDS was compared with the actual value in 2015. Thus, the statistical index was calculated for different models based on 21 monitoring points and is presented in Table 3.

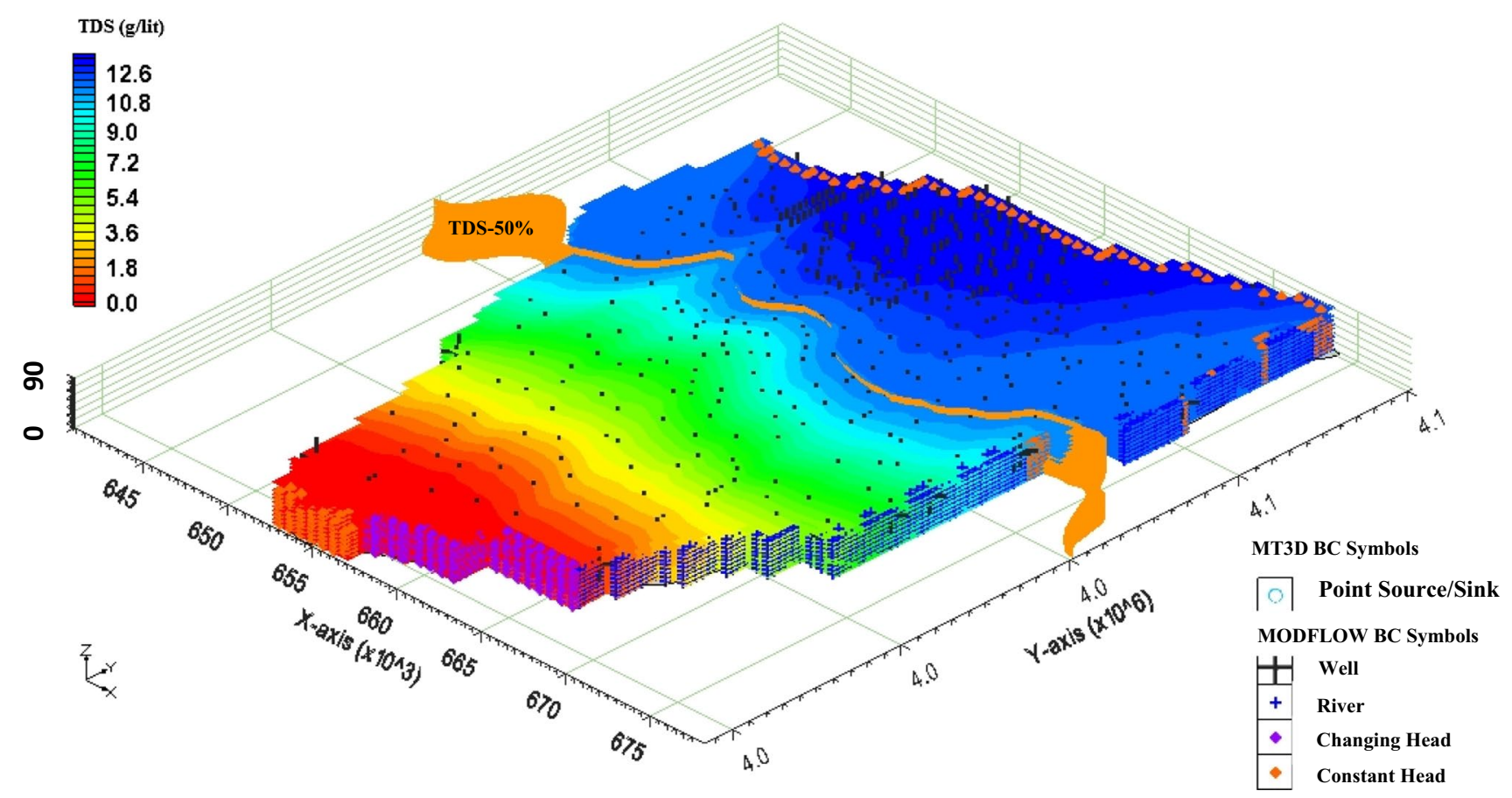

Fig. 4 TDS contour after 1-year stress period in the steady state 


\section{Exponential}

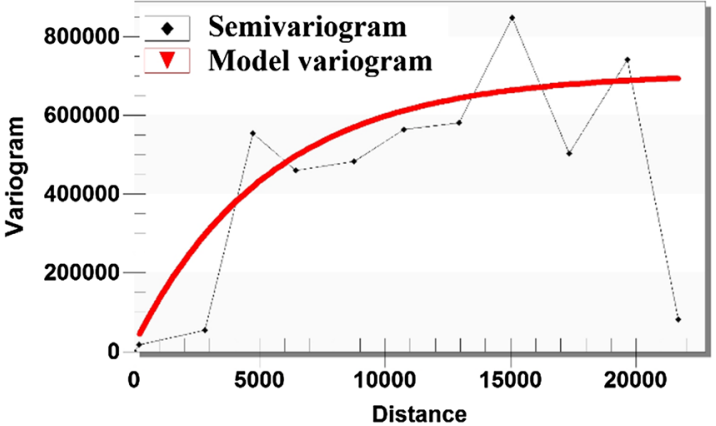

Spherical

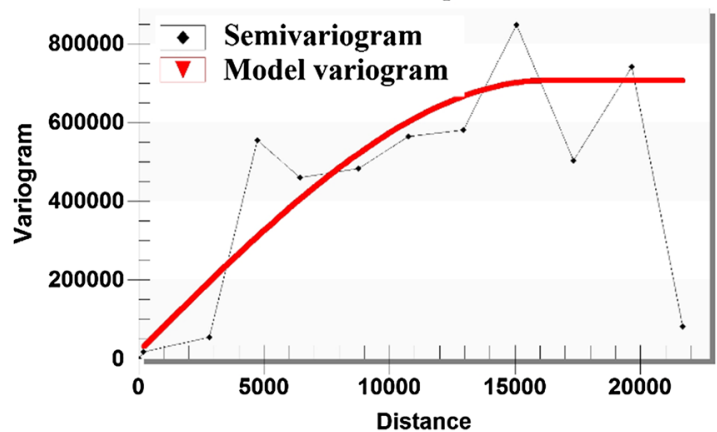

Gaussian

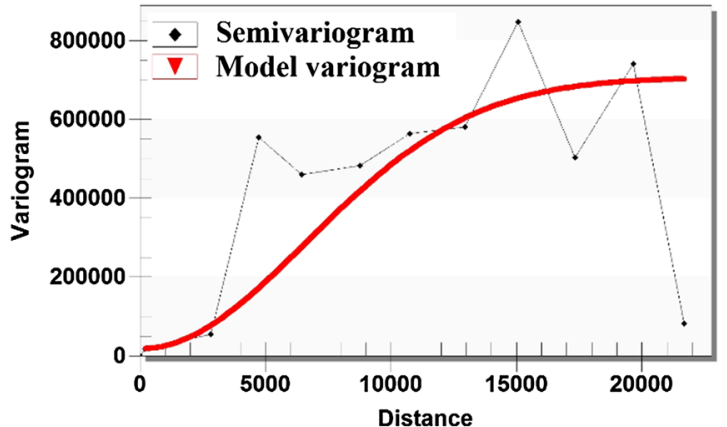

Power

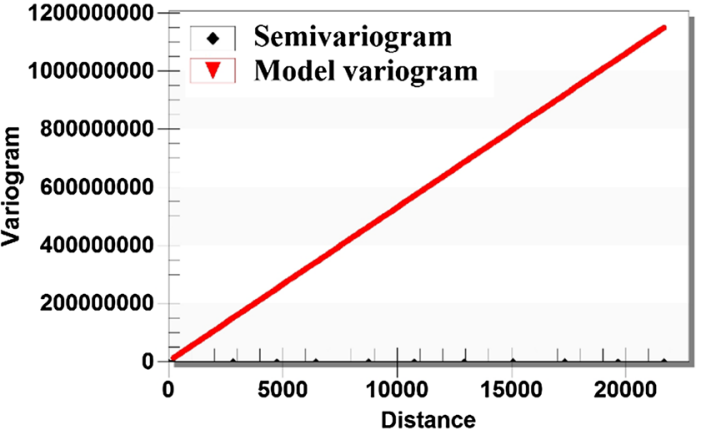

Fig. 5 Optimal variogram versus experimental case

Table 3 Statistical index measures of different variogram to predict spatial variation of TDS in 21 points

\begin{tabular}{llllllll}
\hline Variogram & Mean & SD & Range & CD & MSE & RMSE & $D R_{\max }$ \\
\hline Spherical & 1009 & 296 & 2435 & 0.82 & 66,533 & 258 & -1.22 \\
Exponential & 934 & 263 & 2081 & 0.86 & 59,595 & 244 & -0.14 \\
Gaussian & 911 & 279 & 1789 & 0.87 & 53,372 & 231 & -0.038 \\
Power & 936 & 237 & 2044 & 0.84 & 75,529 & 274 & -0.15 \\
Natural neighbor & 1118 & 449 & 2680 & 0.91 & 64,325 & 253 & -0.28 \\
Inverse distance & 1587 & 1040 & 2680 & 0.59 & 302,695 & 550 & -0.035 \\
\hline
\end{tabular}

Fig. 6 Comparison between the estimated and observed TDS of different spatial variogram

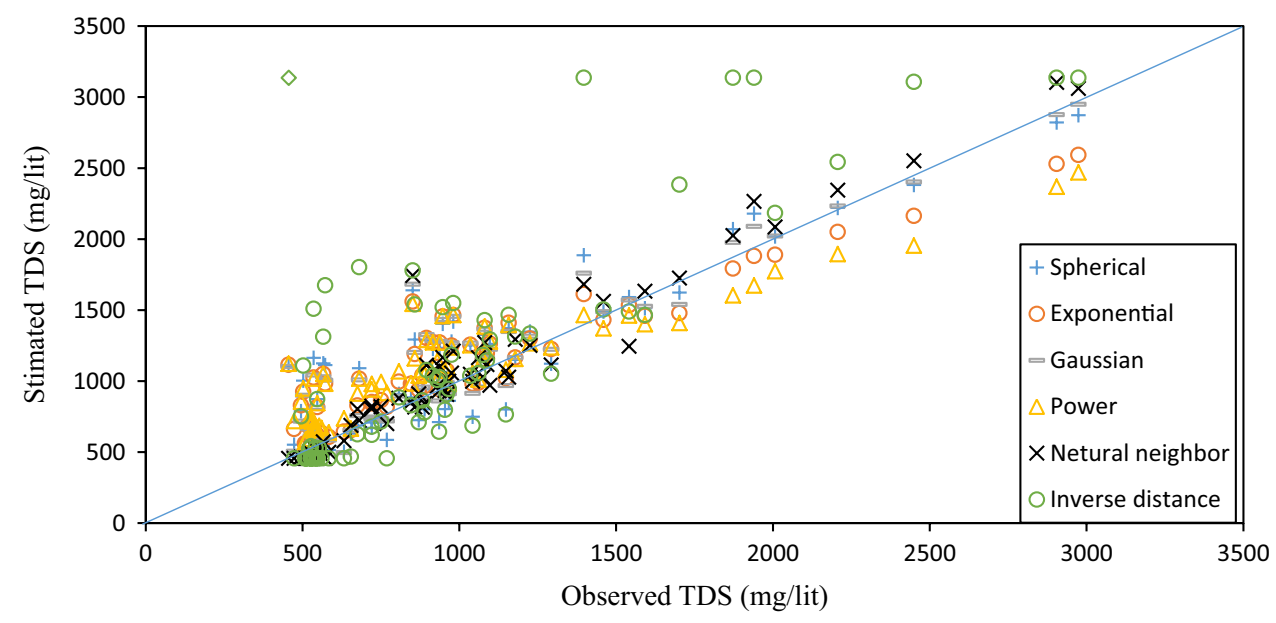


Fig. 7 Spatial distribution of TDS corresponding to different variogram models
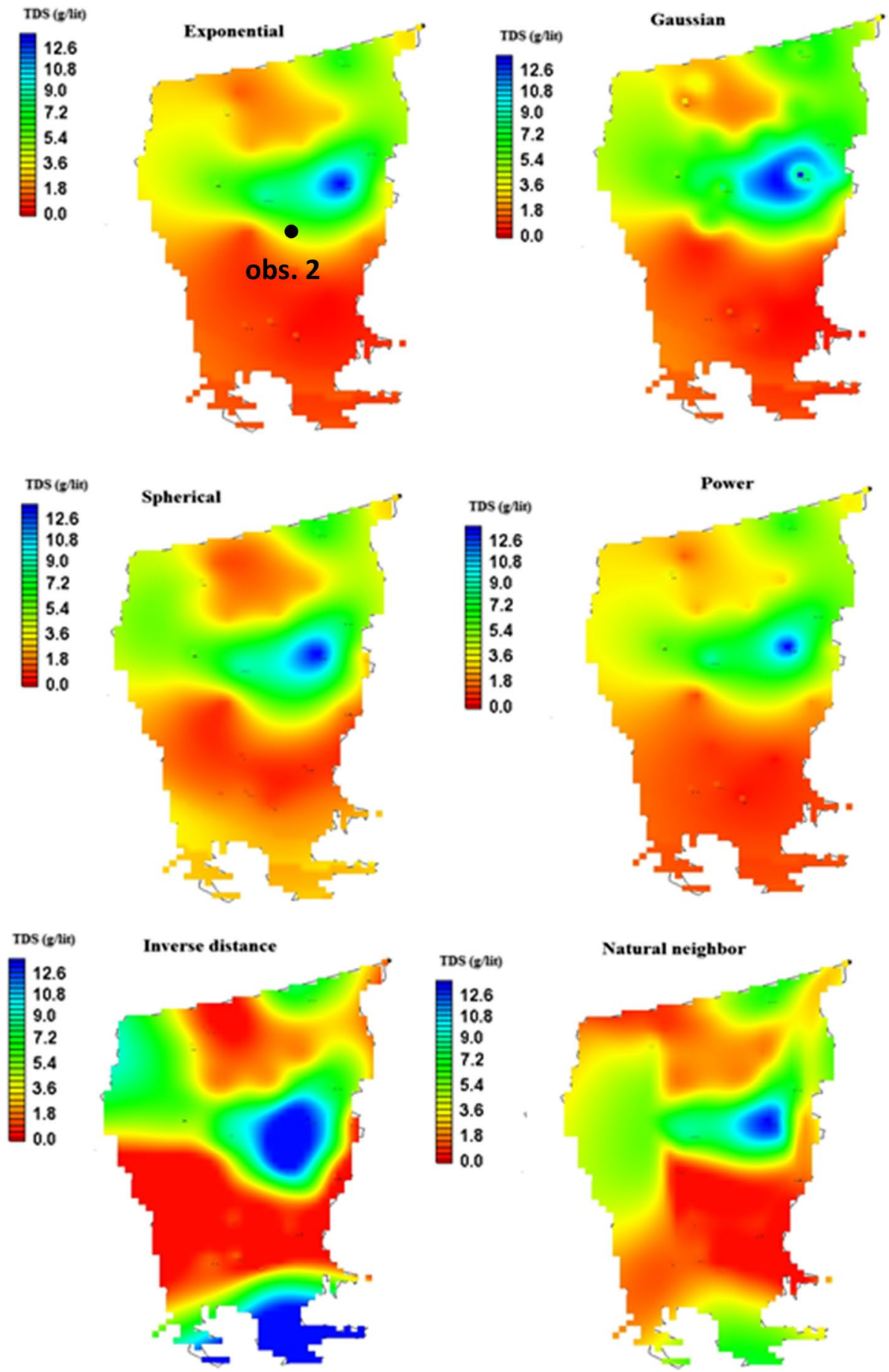

Table 3 shows that the value of $\mathrm{CD}$ among four variogram varies between 0.59 and 0.91 . Between various methods, Gaussian model shows the low MSE (53372) and RMSE (231) with high CD. $D R_{\max }$ is the main factor that indicates the ability of estimation model for peak value of TDS. Regarding the negative value of $D R_{\max }$, it can be concluded that all models underestimate the peak value of TDS. Between all models, Gaussian and spherical model show the lowest and highs $D R_{\max }$ value, respectively. Unlike the inverse distance method, the power variogram underestimates the high value of TDS. Also, the spherical model tends to overestimate the TDS in the points with low value of TDS. As shown in Fig. 6, a goodness of fit with high correlation was observed for exponential variogram. The main reason for this high correlation can be attributed to the consistency of exponential variogram with the sharp variation of TDS from sea boundary to the inland. In this area, the low pumping rate results in constant TDS value. However, the 

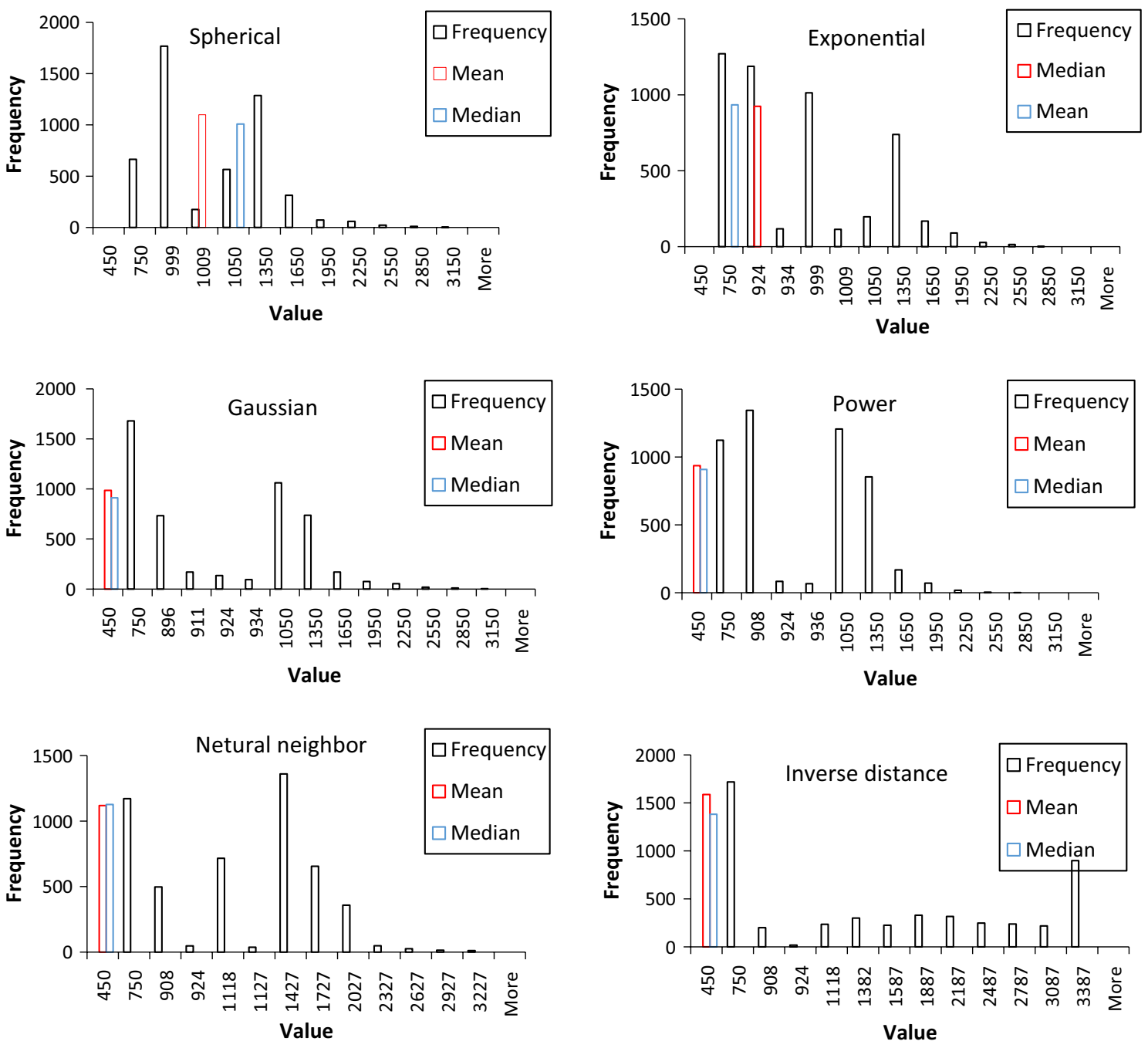

Fig. 8 Histogram of TDS concentration of 3500 cells for different variogram (obs. 2). The red block illustrate the mean value and the green block illustrate the median value

exponential model shows the high MSE for the area which is located near the shoreline. To overcome this problem, the combination of the spherical and exponential model should be used for estimation of TDS in different points.

TDS distribution for first time step is shown in Fig. 7. As seen, a high level of salinity is observed in the center of the Talar aquifer and near the shoreline, where the excessive groundwater was extracted from productions wells. The gradual decrease in TDS from the seaside toward the center of the aquifer is estimated with four variograms. Although variogram models indicate that the upconing happens in the center of the aquifer, however, the variation of TDS in vertical direction should be compared with SEAWAT results. By visual comparison, the power and spherical variogram have similar trend for the peak value of TDS. The spatial variation of TDS indicates that salinity level near the southern side is lower than other parts $\left(4500 \mathrm{mg} \mathrm{L}^{-1}\right)$. Additionally, the yellow color near the sea line is corresponding to the area with low pumping rate in which, saltwater intrusion is lower than other parts.

In Fig. 8, the histogram of estimated TDS for cells near the observation point 2 (see Fig. 7) is illustrated. For spherical and exponential case, the distribution of estimated TDS is less skewed into mean value which causes a smooth variogram. For Gaussian and power case, TDS values are in the range of $0-2550 \mathrm{mg} \mathrm{L}^{-1}$ with a median value about 999 and 936, respectively. For inverse distance and neutral neighbor methods, TDS values are mostly in the range of 450-1650 $\mathrm{mg} \mathrm{L}^{-1}$ with a skewness value of 1.7. These two interpolation methods have the capability for estimation of TDS near the mean value, while all variogram models were appropriate for prediction of peak TDS value. However, the spherical and Gaussian model covers the high range of TDS value between seaside and inland. 

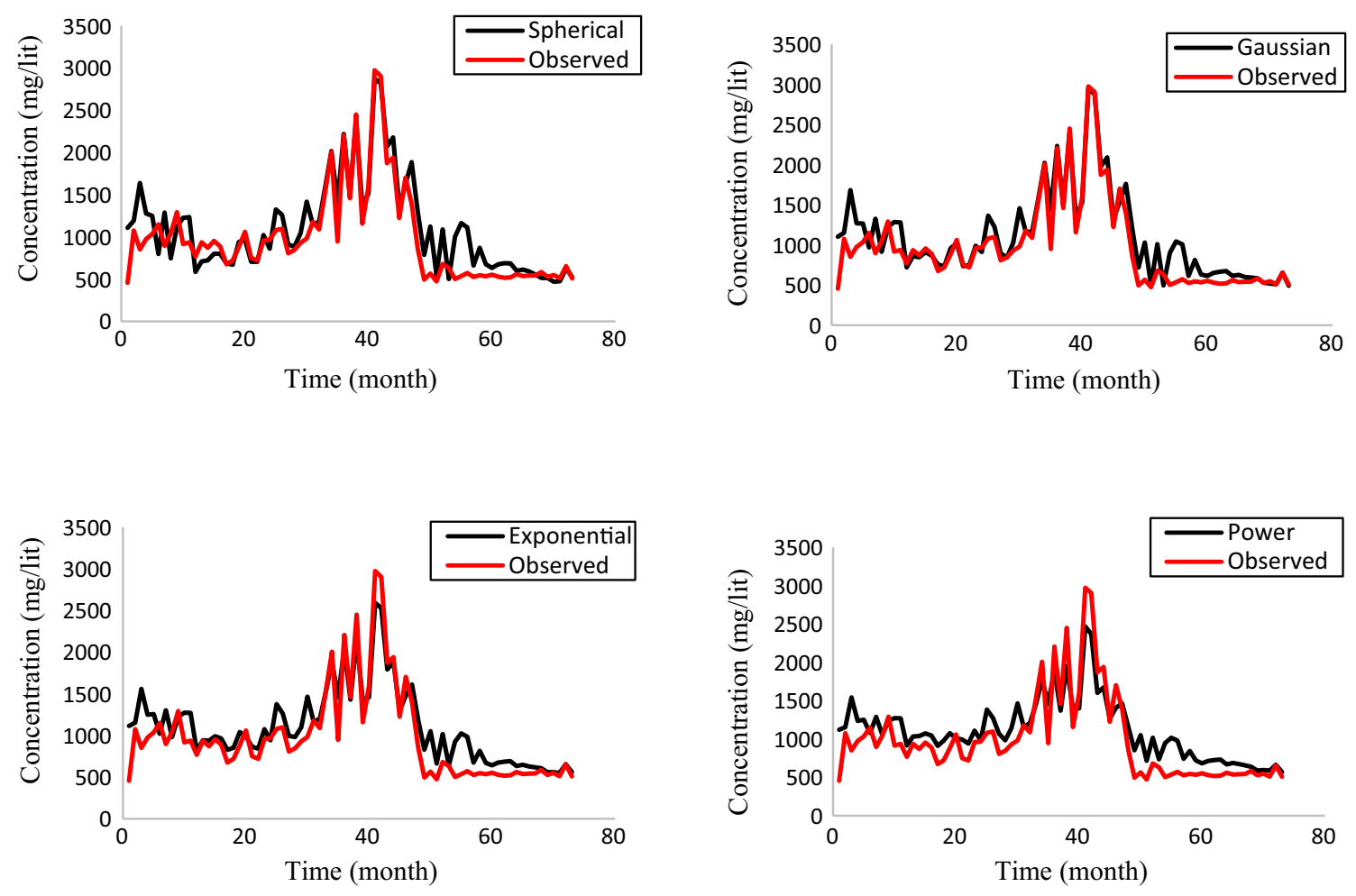

Fig. 9 Temporal variation of TDS in the obs. 2 for observed and predicted data

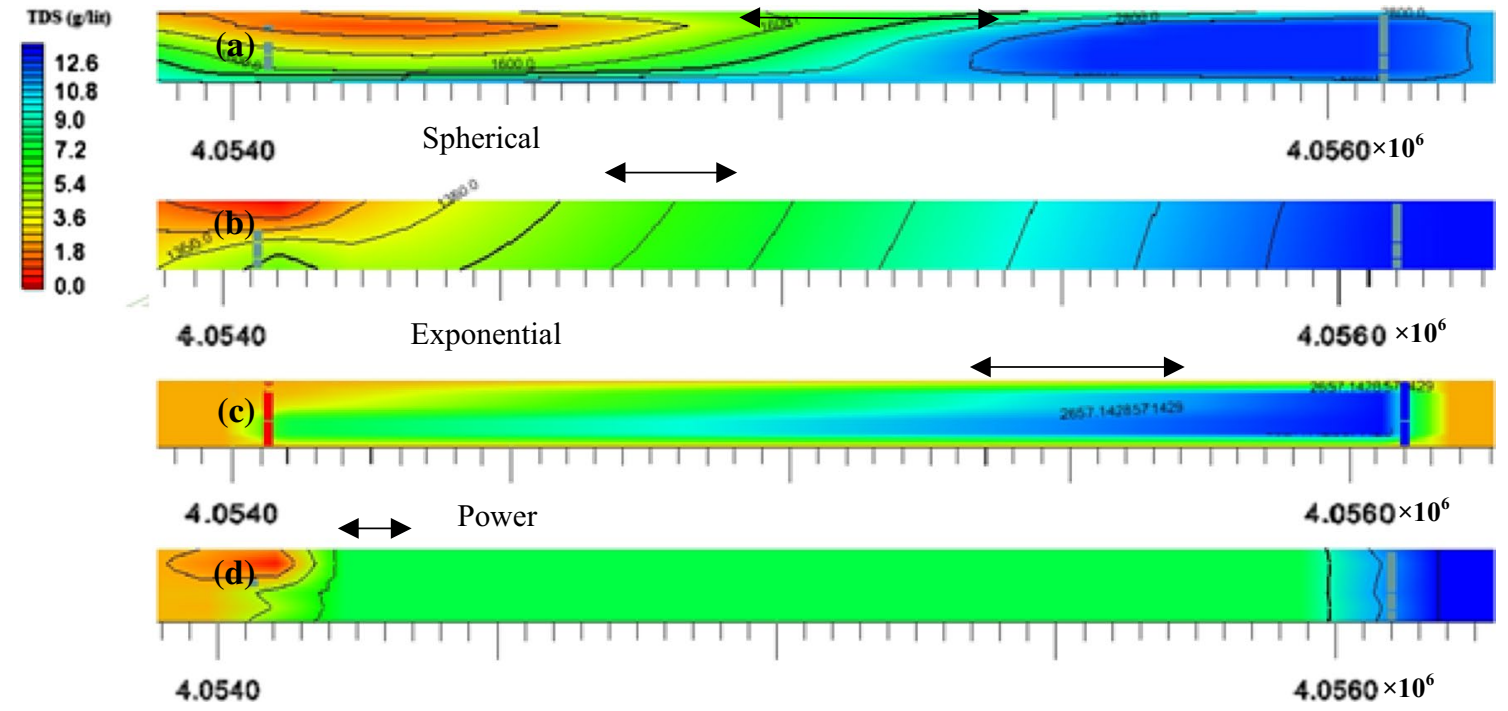

Fig. 10 Vertical profile of saltwater intrusion for different models

Temporal variation of TDS (in obs. 2) for 80 months is shown in Fig. 9. Regardless of the minimum error in peak value, predicted and observed TDS show the similar trend. Moreover, Gaussian and spherical variogram was fitted with the observed curve near the peak value, successfully. For temporal and spatial estimation of TDS, the Gaussian variogram is the best model regarding to the minimum value of MSE and RMSE. Therefore, it can be concluded that the Gaussian model with optimal parameters can be used for the temporal mapping. Although various spatial variogram methods show the acceptable range of statistical indexes for spatial estimation, however, the Gaussian model performs 

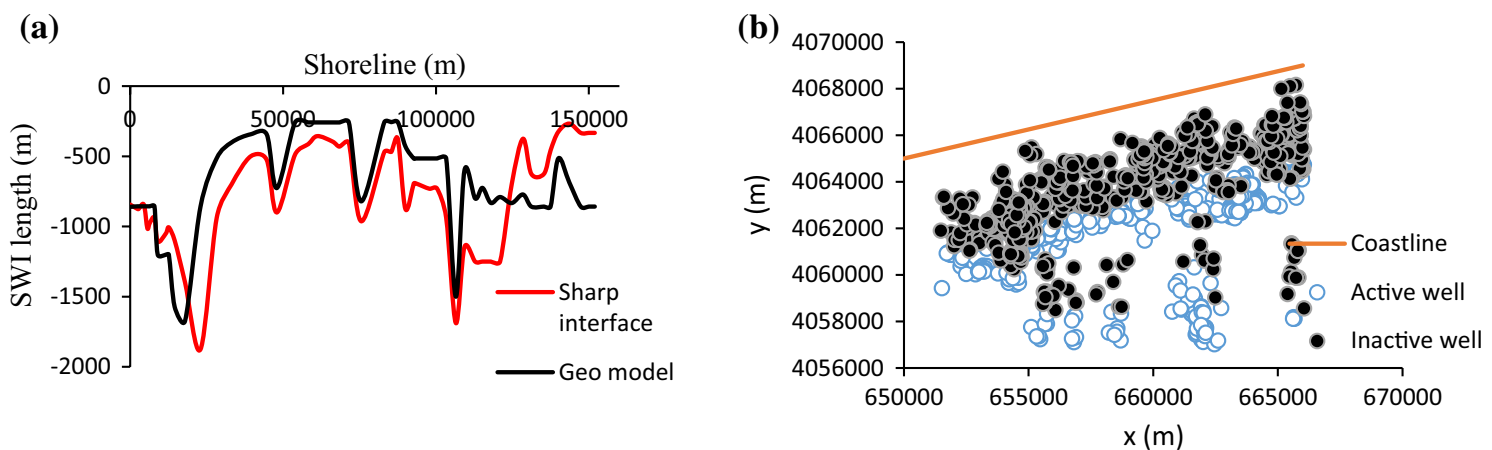

Fig. 11 a Saltwater toe location parallel to shoreline for analytical and geo model, b pumping wells distribution parallel to shoreline

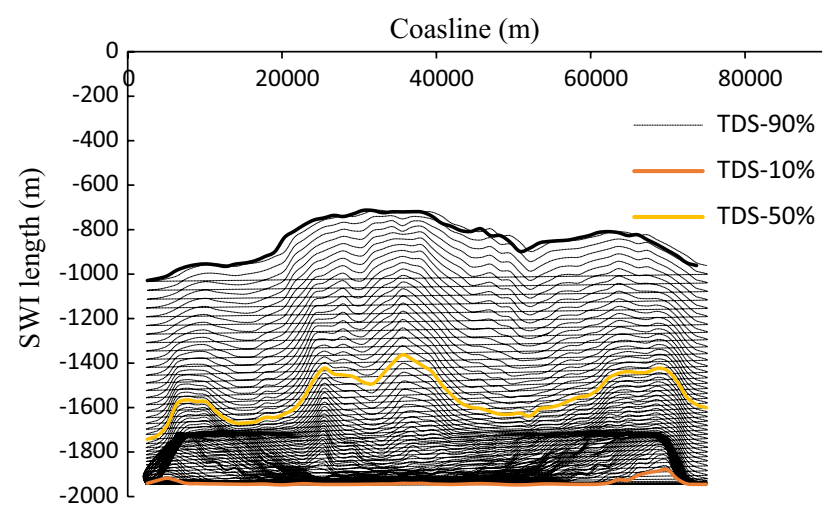

Fig. 12 Simulated TDS contour by SEAWAT model

well in case of spatial and temporal prediction. The implementation of the same variogram for two cases results in the best performance of separable model.

The freshwater and saltwater interface in the cross section A is illustrated in Fig. 10. As seen, the interface for Gaussian model is located about $700 \mathrm{~m}$ of shoreline while, in the spherical and exponential variogram the interface is located about $900 \mathrm{~m}$ and $400 \mathrm{~m}$ of shoreline, respectively.

Among the four models, the Gaussian variogram profile has a similar trend to the sharp interface approach.

Based on sharp interface relationship, the location of saltwater toe considering homogeneous behavior with constant permeability $\left(100 \mathrm{~m}^{2}\right.$ day $\left.^{-1}\right)$ is varied between 844 and $1100 \mathrm{~m}$. A comparison between Gaussian variogram and sharp interface relation in term of interface location was carried out. For the Gaussian model, the location of 0.7TDS $\max \left(8.82 \mathrm{~g} \mathrm{~L}^{-1}\right)$ is considered as the saltwater wedge. As demonstrated in Fig. 11, the interface length for Gaussian model relatively is small than sharp interface relation. This difference can be attributed to neglecting transition zone by sharp interface model. From Fig. 10a, maximum saltwater penetration $(1600 \mathrm{~m})$ is corresponding to the area which have large number of active wells. Interestingly, the area with large pumping rate such as eastern and western part has large interface. Regarding the high pumping rate from the aquifer, the precipitation fluctuant has the negligible effect on saltwater intrusion. Figure 12 shows the TDS distribution simulated by SEAWAT model. As seen, the location of TDS-50\% is located about $1700 \mathrm{~m}$ from shoreline.

\section{Conclusions}

The aim of this study was to develop an optimal variogram for spatio-temporal estimation of salinity in the Talar aquifer. The performance of proposed methodology was examined for the spatial and temporal variation of TDS in heterogeneous aquifer of Talar which has a large number of pumping wells. Different variogram models were developed based on 21 monitoring points, and the structure of each model optimized using GA algorithm. The variogram models with optimal nugget and sill values for the spatial case were used to estimate the variation of TDS for 80 month in the steady state. The optimal Gaussian and exponential model show the low error between experimental and estimated variogram for large and small lags, respectively. Therefore, an integration of two models was used for the prediction of salinity near the shoreline. Gaussian model shows the low MSE with low DR value (0.001) between observed and estimated TDS and indicate its capability for prediction of high TDS. The temporal projection of TDS during the 80-month stress periods indicate that, although the spatially optimized variogram show the relatively high error for temporal case, however, similar trend of RMSE is observed for all variograms. Vertical profile for the Gaussian model shows the interface location in $1200 \mathrm{~m}$ of shoreline. A goodness of fit observed between Gaussian variogram and sharp interface model for prediction of interface length. Additionally, the maximum saltwater penetration based on sharp interface and SEAWAT results is about $1600 \mathrm{~m}$ and $1750 \mathrm{~m}$, respectively. 
This maximum SWI is observed in the western part of aquifer which is threatened by over-pumping.

Open Access This article is distributed under the terms of the Creative Commons Attribution 4.0 International License (http://creativeco mmons.org/licenses/by/4.0/), which permits unrestricted use, distribution, and reproduction in any medium, provided you give appropriate credit to the original author(s) and the source, provide a link to the Creative Commons license, and indicate if changes were made.

\section{References}

Abd-Elhamid HF, Javadi AA (2011) A cost-effective method to control seawater intrusion in coastal aquifers. Water Resour Manag 25(11):2755-2780

Abd-Elhamid H, Javadi A, Abdelaty I, Sherif M (2016) Simulation of seawater intrusion in the Nile Delta aquifer under the conditions of climate change. Hydrol Res 47(6):1198-1210

Agoubi B, Kharroubi A, Abida H (2013) Saltwater intrusion modelling in Jorf coastal aquifer, South-eastern Tunisia: geochemical, geoelectrical and geostatistical application. Hydrol Process 27(8):1191-1199

Akbarzadeh M, Ghahraman B (2013) A combined strategy of entropy and spatio-temporal kriging in determining optimal network for groundwater quality monitoring of Mashhad basin. J Water Soil 27:613-629

Carneiro JF, Boughriba M, Correia A, Zarhloule Y, Rimi A, El Houadi B (2010) Evaluation of climate change effects in a coastal aquifer in Morocco using a density-dependent numerical model. Environ Earth Sci 61(2):241-252

Colombani N, Osti A, Volta G, Mastrocicco M (2016) Impact of climate change on salinization of coastal water resources. Water Resour Manag 30(7):2483-2496

Deutsch CV, Tran TT (2002) FLUVSIM: a program for object-based stochastic modeling of fluvial depositional systems. Comput Geosci 28(4):525-535

Dhar A, Datta B (2009) Logic-based design of groundwater monitoring network for redundancy reduction. J water Resour plan Manag 136(1):88-94

Dhar A, Patil RS (2011) Fuzzy uncertainty based design of groundwater quality monitoring networks. J Environ Res Develop 5(3A)

Diersch HJG (2005) FEFLOW finite element subsurface flow and transport simulation system. Institute for Water Resources Planning and System Research, Berlin

Dokou Z, Karatzas GP (2012) Saltwater intrusion estimation in a karstified coastal system using density-dependent modelling and comparison with the sharp-interface approach. Hydrol Sci J 57(5):985-999

Fatemi E, Ataie-Ashtiani B (2008) "Simulation of seawater intrusion effect on contaminant transport in coastal aquifer of Tallar", 4th National Congress of Civil Engineering, Tehran university in Iran (in Persian)

Fuentes M, Chen L, Davis JM (2008) A class of nonseparable and nonstationary spatial temporal covariance functions. Environmetrics 19(5):487-507

Gneiting T, Genton MG, Guttorp P (2006) Geostatistical space-time models, stationarity, separability, and full symmetry. Monogr Stat Appl Probab 107:151

Gopinath S, Srinivasamoorthy K, Saravanan K, Suma CS, Prakash R, Senthilnathan D, Sarma VS (2016) Modeling saline water intrusion in Nagapattinam coastal aquifers, Tamilnadu, India. Model Earth Syst Environ 2(1):2
Huang G, Sun J, Zhang Y, Chen Z, Liu F (2013) Impact of anthropogenic and natural processes on the evolution of groundwater chemistry in a rapidly urbanized coastal area, South China. Sci Total Environ 463:209-221

Khattak A, Ahmed N, Hussain I, Qazi MA, Khan SA (2014) Spatial distribution of salinity in shallow ground water used for crop irrigation. Pak J Bot 46(2):531-537

Kitanidis PK (1997) Introduction to geostatistics: applications in hydrogeology. Cambridge University Press, Cambridge

Kourakos G, Mantoglou A (2009) Pumping optimization of coastal aquifers based on evolutionary algorithms and surrogate modular neural network models. Adv Water Resour 32(4):507-521

Kumar P, Bansod BK, Debnath SK, Thakur PK, Ghanshyam C (2015) Index-based groundwater vulnerability mapping models using hydrogeological settings: a critical evaluation. Environ Impact Assess Rev 51:38-49

Langevin CD, Zygnerski M (2013) Effect of Sea-Level rise on salt water intrusion near a coastal well field in southeastern Florida. Groundwater 51(5):781-803

Langevin CD, Thorne Jr DT, Dausman AM, Sukop MC, Guo W (2008) SEAWAT version 4: a computer program for simulation of multispecies solute and heat transport (No. 6-A22). Geological survey (US)

Liebhold AM, Rossi RE, Kemp WP (1993) Geostatistics and geographic information systems in applied insect ecology. Annu Rev Entomol 38(1):303-327

Lin HJ, Rechards DR, Talbot CA, Yeh GT, Cheng JR, Cheng HP, Jones NL (1997) A three-dimensional finite-element computer model for simulating density-dependent flow and transport in variable saturated media: version 3.1. US Army Engineering Research and Development Center, Vicksburg, MS

Lu W, Yang Q, MARTÍN JD, Juncosa R (2013) Numerical modelling of seawater intrusion in Shenzhen (China) using a 3D density-dependent model including tidal effects. J Earth Syst Sci 122(2):451-465

Lu C, Xin P, Li L, Luo J (2015) Seawater intrusion in response to sealevel rise in a coastal aquifer with a general-head inland boundary. J Hydrol 522:135-140

Mahdianfard N, Mohammadzadeh M (2015) Bayesian melding of deterministic models and Kriging for analysis of spatially correlated data. modern research physics 17(40):85-98

Maschio C, Vidal AC, Schiozer DJ (2008) A framework to integrate history matching and geostatistical modeling using genetic algorithm and direct search methods. J Petrol Sci Eng 63(1):34-42

Mazi K, Koussis AD, Destouni G (2013) Tipping points for seawater intrusion in coastal aquifers under rising sea level. Environ Res Lett 8(1):014001

Nocchi M, Salleolini M (2013) A 3D density-dependent model for assessment and optimization of water management policy in a coastal carbonate aquifer exploited for water supply and fish farming. J Hydrol 492:200-218

Oliver MA (ed) (2010) An overview of geostatistics and precision agriculture. In: Geostatistical applications for precision agriculture. Springer, Dordrecht, pp 1-34

Pool M, Post VE, Simmons CT (2014) Effects of tidal fluctuations on mixing and spreading in coastal aquifers: homogeneous case. Water Resour Res 50(8):6910-6926

Ranjbar A, Mahjouri N (2018) Development of an efficient surrogate model based on aquifer dimensions to prevent seawater intrusion in anisotropic coastal aquifers, case study: the Qom aquifer in Iran. Environ Earth Sci 77:418

Roy DK, Datta B (2017) Saltwater intrusion processes in coastal aquifers-modelling and management: a review. Desalin Water Treat 78:57-89

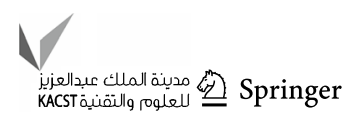


Sadeghiyan A, Vagheiy Y, Mohammadzadeh M (2013) Spatial-temporal prediction of groundwater level in Birjand region using Kriging method. Water Wastewater 24(1):94-100

Schabenberger O, Gotway CA (2017) Statistical methods for spatial data analysis. CRC Press, Boca Raton

Strack ODL (1976) A single-potential solution for regional interface problems in coastal aquifers. Water Resour Res 12(6):1165-1174

Tomaszkiewicz M, Najm MA, El-Fadel M (2014) Development of a groundwater quality index for seawater intrusion in coastal aquifers. Environ Model Softw 57:13-26

Triki C, Oprea S, Beraldi P, Crainic TG (2014) The stochastic bid generation problem in combinatorial transportation auctions. Eur J Oper Res 236(3):991-999

Venkatramanan S, Chung SY, Kim TH, Kim BW, Selvam S (2016) Geostatistical techniques to evaluate groundwater contamination and its sources in Miryang City, Korea. Environ Earth Sci 75(11):1-14

Voss CI (1984) A finite-element simulation model for saturated-unsaturated, fluid-density-dependent ground-water flow with energy transport or chemically-reactive single-species solute transport. US Geol Surv, Reston, p 409
Werner AD, Bakker M, Post VE, Vandenbohede A, Lu C, Ataie-Ashtiani B, Barry DA (2013) Seawater intrusion processes, investigation and management: recent advances and future challenges. Adv Water Resour 51:3-26

Yoo EH, Brown P, Eum Y (2018) Ambient air quality and spatiotemporal patterns of cardiovascular emergency department visits. Int J Health Geograph 17(1):18

Zheng C, Wang PP (1999) MT3DMS: a modular three-dimensional multispecies transport model for simulation of advection, dispersion, and chemical reactions of contaminants in groundwater systems; documentation and user's guide. Alabama Univ University

Zeng X, Wu J, Wang D, Zhu X (2016) Assessing the pollution risk of a groundwater source field at western Laizhou Bay under seawater intrusion. Environ Res 148:586-594

Publisher's Note Springer Nature remains neutral with regard to jurisdictional claims in published maps and institutional affiliations. 